\title{
PENGARUH INTERVENSI KOGNITIF SPIRITUAL TERHADAP PENERIMAAN DIRI PADA KLIEN STROKE ISKEMIK
}

\author{
Novita Setyowati*, Uswatun Hasanah** \\ - Akper Dharma Husada Kediri \\ ** RSUD Kota Probolinggo
}

\begin{abstract}
Hemiparese is a common problem that can caused disability. Exercise is still considered effective to prevent disability. This study is aimed to increased the muscle strength on hemiparese patient's muscle strength caused by ischemic stroke in RSUD Gambiran Kota Kediri. This study used Quasi Experiment pre and post test research designs. Number of samples were 9 respondents who were divided into intervention group and control group. Evaluation research was done on the first day and eigth day for the two groups. Data were analyzed Paired T test and Independent T Test. Study results showed an increased in muscle strength $(\mathrm{p}=0.000)$ in both the intervention groups and there are significant differences between the two groups $(p=0009)$, which means there is a difference between the control group treatment group. The implication of this research are to use exercise as one of the independent nursing interventions in caring stroke patients with hemiparase and to improve the quality of nursing care, makes healing process faster, prevent complications dan also enrich nursing science.
\end{abstract}

\section{Keywords: stroke; hemiparese; Spiritual intervention on cognitive; Self acceptance .}

\section{PENDAHULUAN}

Stroke merupakan gangguan fungsi otak akibat terganggunya aliran darah di otak yang sering menyebabkan kematian dan kecacatan. Klien stroke yang selamat dari kematian, $64 \%$ diantaranya mengalami gangguan kognitif dengan berbagai tingkatan dan sepertiganya akan mengalami demensia (Chiu et al, 2013; Aguayo et al, 2014). Gangguan kognitif dan perubahan fisik menyebabkan klien sulit menerima kondisinya, sehingga muncul perasaan sedih, marah, tidak berguna, putus asa dan merasa lemah (Townend et al, 2010; Rohadirja, 2012; Sun, 2014). Perasaan tidak berguna akibat peran sebagai kepala keluarga, pencari nafkah, pekerja, ibu rumah tangga sebagai pusat pengatur keluarga yang selama ini melekat tidak berfungsi optimal menjadi pemicu munculnya pikiran negatif. Pikiran negatif dapat menyebabkan gangguan penerimaan diri akibat respon adaptasi terhadap perubahan pasca stroke yang tidak adaptif. Intervensi kognitif spiritual dapat membantu mengubah pikiran negatif menjadi pikiran positif dengan mengoptimalkan spiritualitas klien melalui murotal QS. Ar-Rahman. Munculnya pikiran positif pada diri klien dapat mempercepat proses adaptasi klien stroke sehingga klien menjadi acceptance terhadap perubahan pasca stroke dan penerimaan diri klien meningkat.

Penelitian pada 100 klien stroke menyatakan bahwa gangguan kognitif dan ketidakmampuan fisik pada klien stroke memiliki korelasi negatif dengan keputusasaan (Ardi, 2011). Semakin tinggi derajat gangguan kognitif dan ketidakmampuan fisik, maka keputusasaan klien stroke semakin besar.

World Health Organization (WHO) memprediksi tahun 2020 stroke menjadi penyakit kedua setelah jantung iskemik sebagai penyebab kecacatan di dunia. Stroke terbagi menjadi dua jenis yaitu stroke iskemik dan hemoragik. Prevalensi kejadian stroke iskemik lebih tinggi dibandingkan stroke hemoragik yaitu 80 $85 \%$ dari seluruh kejadian stroke. Meskipun demikian, angka harapan hidup 
stroke iskemik lebih baik daripada stroke hemoragik (Misbach \& Kalim, 2007). Tahun 2009 jumlah penderita stroke di Amerika berada di urutan ketiga, bertambah 795.000 orang setiap tahunnya yang 636.000 orang diantaranya adalah penderita stroke iskemik dan mengakibatkan 150.000 kematian. Penderita stroke membutuhkan biaya 21,8 juta dolar untuk pelayanan kesehatan langsung dan 65,5 juta dolar untuk pelayanan kesehatan tidak langsung.

Jumlah penderita stroke di Indonesia semakin meningkat (Riskesdas, 2013). Tahun 2007 penderita stroke naik dari 8,3 menjadi 12,1, per 1000 penduduk pada tahun 2013 dan Jawa Timur menempati urutan keempat jumlah penderita stroke setelah Sulawesi Selatan, DI Yogyakarta dan Sulawesi Tengah dengan 16 orang penderita stroke per 1000 penduduk. Tingginya angka kejadian dan biaya untuk menangani penderita stroke ini membutuhkan penanganan serius untuk mencegah terjadinya peningkatan angka kejadian stroke dan serangan stroke berulang.

Otak sebagai saraf pusat mempunyai salah satu peran yaitu mengatur fungsi kognitif yang diatur oleh sistem limbik. Sistem limbik mencakup thalamus, ganglia basalis, serebelum, lobus frontal, lobus temporal, lobus parietal, lobus oksipital dimana setiap lobus memiliki peran dalam mengatur fungsi kognitif. Gangguan kognitif dan emosi pada klien stroke disebabkan oleh faktor neurobiologi dan psikologi. Faktor neurobiologi yaitu kerusakan anatomi dan vaskularisasi di otak yang menyebabkan ketidakseimbangan neurotransmitter dan menyebabkan gangguan perilaku dan emosional. Sedangkan faktor psikologi adalah stressor berupa kehilangan atas kemampuan yang dimiliki sebelumnya (Wicaksana, 2008).

Gangguan kognitif pada klien stroke diukur dengan menggunakan (MMSE)Mini Mental State Examination. Khadr (2009) menyatakan diantara 81 orang klien stroke iskemik (84\%) dan stroke hemorhagik (16\%) fase akut didapatkan rerata nilai MMSE 25,58 \pm 2,95. Sedangkan Sutomo (2013) menemukan bahwa klien pasca stroke 68,1\% memiliki nilai MMSE pada rentang fungsi kognitif normal dan $25 \%$ pada gangguan kognitif ringan. Ratnasari (2010) menyatakan rerata klien stroke iskemik serangan pertama memiliki nilai MMSE 24,20 $\pm 3,098$ dan klien stroke iskemik serangan ulang memiliki rerata $19,87 \pm 4,257$

Selama menjalani perawatan dan rehabilitasi, klien stroke memiliki perasaan negatif tentang diri mereka, penurunan aktivitas sosial dan gangguan psikologis. Keadaan ini terjadi akibat gangguan aliran darah yang dapat menurunkan sintesis monoamin sehingga terjadi penurunan serotonin sebagai neuroransmitter untuk mempertahankan keadaan emosi agar tetap stabil (Cass, 2008; Elis \& Horn, 2000). Penurunan serotonin menyebabkan gangguan suasana hati, tidur dan nafsu makan (Schub \&Caple, 2010). Gangguan suasana hati dimanifestasikan dalam bentuk marah, frustasi, putus asa dan sering menyebabkan depresi (Green \& King, 2007). Selain itu kecacatan yang dialami menimbulkan perasaan tidak berguna, tidak ada gairah dan keputusasaan dan berujung pada gangguan penerimaan diri. Insiden gangguan penerimaan diri pada klien stroke di Taiwan diteliti oleh Chiu et al (2013) yang menyatakan rerata nilai penerimaan diri klien stroke berada pada tingkat rendah dengan nilai 71.72 (kisaran nilai 32-128). Townend et al (2010) menyatakan bahwa sepertiga klien stroke mengalami depresi akibat gangguan penerimaan diri dan mengungkapkan rasa sedih dan tidak berguna akibat menderita stroke. Pikiran negatif yang muncul pada klien stroke dapat menyebabkan klien menjadi depresi. Pikiran negatif tersebut harus dirubah menjadi pikiran positif dengan menggunakan intervensi kognitif spiritual yang bertujuan untuk merubah 
pikiran negatif klien menjadi pikiran positif berbasis spiritual dengan menggunakan QS Ar-Rahman ayat 1-78.

Pada klien hipertensi pemberian intervensi murotal QS. Ar-Rahman dapat menurunkan tekanan darah (Ernawati, 2013). Penelitian lain menemukan bahwa Murotal QS Ar-Rahman dapat menurunkan perilaku kekerasan di RSJD Dr. Amino Gondohutomo Semarang (Widhowati, 2010). Murotal QS ArRahman juga dapat menurunkan kecemasan pada lansia (Novianti, 2012). Pemberian murrotal QS. Ar-Rahman akan menimbulkan rasa percaya diri, rasa optimisme (harapan kesembuhan), mendatangkan ketenangan, damai dan merasakan kehadiran Tuhan sehingga mengakibatkan rangsangan ke hipotalamus untuk menurunkan produksi CRF (Corticotropin Releasing Factor). $\mathrm{CRF}$ akan merangsang kelenjar pituitary anterior untuk menurunkan produksi ACTH (Adeno Cortico TropinHormon) dan menstimulasi produksi endorphin yang akan membuat klien menjadi relaks. Penurunan ACTH dan peningkatan endorphin juga dapat menurunkan tahanan perifer dan cardiac output sehingga tekanan darah menurun (Reyes, 2006 dan Valentino, 2008).

Intervensi kognitif yang diberikan bersamaan dengan intervensi psikoedukasi pada klien stroke di RS Ciptomangunkusumo mampu menurunkan kondisi depresi dan ketidakberdayaan serta peningkatan kemampuan mengubah pemikiran negatif, dibandingkan jika hanya diberikan intervensi kognitif saja (Ramadia, 2013). Penelitian yang memperdengarkan QS. Ar-Rahman pada klien memiliki efek positif terhadap kecemasan, perilaku kekerasan dan tekanan darah. Dua intervensi ini menarik penulis mempelajari lebih lanjut dan memodifikasi keduanya dengan membuktikan pengaruh intervensi kognitif spiritual pada penerimaan diri pada klien stroke iskemik.

\section{METODE PENELITIAN}

Desain penelitian ini adalah quasi eksperimen dengan rancangan pre-post test design with control group. Populasi dalam penelitian ini adalah semua pasien stroke iskemik fase pasca akut yang dirawat di RS Haji Surabaya Teknik pengambilan sampel adalah consecutive sampling dengan jumlah sampel akhir dengan menambahkan proporsi drop out adallah 10 klien dan klien setiap kelompok.

Instrumen yang digunakan dalam penelitian ini untuk pengukuran fungsi kognitif menggunakan Mini Mental Statae Examination (MMSE), skala penerimaan diri berdasarkan Acceptance of Disability Scale Revised yang diambil 32 pernyataan untuk mengukur penerimaan diri klien.

Analisis data yang digunakan untuk mengetahui perbedaan skala penerimaan diri sebelum dan sesudah pelaksanan intervensi adalah uji Paired $t$ Test. Sedangkan analisis data yang digunakan untuk menguji beda dua kelompok, antara kelompok intervensi dan kelompok pembanding menggunakan Independent $t$ Test.

Tahap penerimaan diri diuji dengan menggunakan Mann Whitney untuk membandingkan pre test dan post test. Sedangkan tahap penerimaan diri antara kelompok perlakuan dan pembanding diuji dengan menggunakan Wilcoxon. 
HASIL PENELITIAN

Data Umum

Tabel 5.1 Distribusi Frekuensi Pada Klien

Stroke Iskemik di RS Haji

Surabaya

\begin{tabular}{llcc}
\hline No & Karakteristik & $\begin{array}{c}\text { Kelompok } \\
\text { perlakuan }\end{array}$ & $\begin{array}{c}\text { Kelompok } \\
\text { pembanding }\end{array}$ \\
\cline { 3 - 4 } & n $\%$ & n $\%$
\end{tabular}

sejumlah 10 responden $(50.0 \%)$ sedangkan pekerjaan klien stroke iskemik paling sedikit adalah lain-lain $(15.0 \%)$. Klien yang tidak memiliki riwayat hipertensi sebanyak 13 orang (65\%).

Total

\section{Da姑 Khusus}

Hasil penilaian skala penerimaan diri



responden didapatkan rentang usia yang mengalami stroke iskemik terbanyak adalah usia 55-64 tahun sejumlah 10 orang $(50 \%)$. Rentang usia responden dibuat berdasarkan pembagian rentang usia Depkes pada Riskesdas 2013. Sedangkan usia pasien stroke iskemik paling sedikit adalahrentang usia 35-444 dan lebih dari 75 tahun yaitu masingmasing satu orang $(5 \%)$.

Pada tabel diatas terlihat bahwa jenis kelamin klien Stroke iskemik terbanyak adalah perempuan yaitu sejumlah 11 responden $(55.00 \%)$ sedangkan jenis kelamin klien Stroke Iskemik paling sedikit adalah laki-laki (45.0\%).

Pendidikan klien stroke iskemik terbanyak adalah SMU yaitu sejumlah 11 responden $(55.0 \%)$ sedangkan pendidikan klien Stroke Iskemik paling sedikit adalah S1 $(5.0 \%)$. Karakteristik pekerjaan klien stroke iskemik terbanyak adalah tidak bekerja atau ibu Rumah tangga yaitu
Berdasarkan tabel diatas rata-rata skor skala penerimaan diri pada pre test kelompok perlakuan adalah 61,9. Terdapat peningkatan rerata pada post test yaitu 72,40. Hasil uji statistik didapatkan $p=0.001$ disimpulkan terdapat perbedaan bermakna pada penilaian yang kedua atau ada perbedaan yang signifikan antara skor skala penerimaan diri pada pre dan post test $(p=0.001 ; \alpha=0.005)$

Rata-rata skor skala penerimaan diri pada pre test kelompok pembanding adalah 55.30. Terdapat peningkatan ratarata skor skala penerimaan diri pada post test yaitu 63,7. Hasil uji statistik didapatkan $p=0.001$ disimpulkan bahwa terdapat peningkatan skala penerimaan diri yang bermakna pada penilaian yang kedua atau ada perbedaan signifikan antara skor skala penerimaan diri antara pre dan post test $(p=0.001 ; \alpha=0.05)$ 
$\begin{array}{cccc}\text { Hasil uji } & \text { Independent } & t & \text { Test } \\ \text { didapatkan } & & \text { nila } & \mathrm{i} p=0.008\end{array}$

sehinggadisimpulkan ada perbedaan yang signifikan setelah dilakukan intervensi pada kelompok perlakuan dibandingkan dengan kelompok pembanding $(p=0.008$; $\alpha=0.05$ ).

\section{PEMBAHASAN}

\section{Gambaran skala penerimaan diri pada klien stroke iskemik}

Skala penerimaan diri klien stroke iskemik di instalasi rawat inap RS Haji Surabaya tergolong rendah yaitu rerata 55.3 pada klien kelompok pembanding dan 61.9 pada kelompok perlakuan. Rentang nilai skala penerimaan diri dari 32 sampai 128 dengan kisaran nilai sedang pada 64-96 menunjukkan bahwa skala penerimaan diri mereka yang masuk pada kategori rendah. Hasil ini menunjukkan kesesuaian dengan penelitian sebelumnya. Nilai ini bahkan lebih rendah bila dibandingkan dengan rerata skala penerimaan diri pada klien stroke di Taiwan (Chiu et al, 2013) dengan nilai 71.2 menggunakan instrumen yang sama.

Penerimaan diri yang rendah dapat menyebabkan klien stroke menjadi stres dan bila tidak ditangani akan menjadi depresi. Perubahan fisik yang terjadi seperti kehilangan kemampuan pergerakan karena penurunan kekuatan otot, kehilangan kemampuan untuk berbicara normal karena afasia, merasa diri menjadi beban dalam keluarga membuat ketidakmampuan klien menjadi fokus utama mereka dan sebagai satu pikiran negatif yang selalu muncul dalam benak klien. Ketika klien selalu berkutat dengan pikiran negatifnya maka klien akan cenderung depresi dan klien stroke yang mengalami depresi sepertiganya akan mengalami serangan ulang dan dapat menyebabkan kematian.

Rentang skala penerimaan diri rendah ini dapat dilihat dari kuesioner skala peneriman diri yang pada penyataan bernilai rendah yang menyatakan bahwa klien setuju bahwa ketidakmampuan mempengaruhi semua aspek kehidupannya. Hampir semua klien stroke mengatakan bahwa ketidakmampuan akibat stroke ini mempengaruhi kehidupan mereka. Demikian juga pada pernyataan bahwa sekuat apapun klien berusaha, maka hasilnya tidak akan sama seperti sebelum mengalami sakit.

Penyataan ketidakmampuan fisik mempengaruhi mental seseorang juga disetujui sebagian besar responden yang menyebabkan rentang skala penerimaan diri menjadi rendah. Klien stroke iskemik dengan kelemahan masih fokus pada kelemahan diri dan belum bisa menemukan hal positif dari diri untuk bisa bangkit dari kesedihan. Hal ini yang harus dibantu oleh perawat agar klien bisa menemukan sisi positif diri sehingga klien dapat menerima kondisi diri sehingga penerimaan diri dapat meningkat.

Pernyataan pada kuesioner skala penerimaan diri bahwa penampilan fisik merupakan hal yang terpenting dalam kehidupan mereka tidak disetujui oleh banyak responden menunjukkan klien dapat menerima kelemahan diri mereka. Pernyataan bahwa ketidakmampuan membuat hampir semua aspek kehidupan tertutup untuk mereka dan ketidakmampuan menghalangi mereka melakukan apapun dan menghalangi mereka untuk menjadi orang baik juga ditolak oleh sebagian besar responden sehingga dapat meningkatkan nilai skala penerimaan diri mereka.

Nilai skala penerimaan diri tetap pada pre dan post test dialami oleh beberapa responden. Nilai skala penerimaan diri rentang rendah dan tidak mengalami peningkatan dialami oleh responden dengan frekuensi kedekatan dengan Qur'an berupa jarang mendengarkan murotal Qur'an. Frekuensi interaksi dengan Qur'an dan tidak mendapatkan intervensi berupa murotal QS Ar-Rahman menyebabkan klien tidak dapat menemukan sisi positif diri sehingga skala penerimaan diri klien rendah dan tidak 
meningkat. Klien yang memiliki nilai skala penerimaan diri tinggi sejak pre test dan tidak mengalami peningkatan pada post test dialami oleh klien yang frekuensi kedekatan dengan Qur'an berupa biasa mendengarkan murotal Qur'an. Klien berusia 67 dengan pendidikan SD dan klien merasa sudah bisa menerima kondisi penyakitnya membuat klien mengisi kuesioner post test dengan jawaban yang sama dengan pre test. Pendidikan yang rendah, usia lanjut dan kelelahan fisik inilah yang membuat klien engan untuk mengisi post test dengan data baru dan mengisi dengan jawaban yang sama.

Berdasarkan tabel 5.1, jenis kelamin klien stroke iskemik pada penelitian ini didominasi oleh perempuan sebanyak 11 (55\%) dari 20 responden. Hal ini tidak sesuai dengan penelitian yang dilakukan leh Lewis (2007) dan Cin-Ying et al (2010) yang menyatakan bahwa jenis kelamin laki-laki memiliki resiko lebih tinggi terkena stroke dibandingkan dengan perempuan. Lelaki dinyatakan memiliki resiko lebih tinggi karena gaya hidup seperti merokok, minum minuman beralkohol, penggunaan obat-obatan dan faktor stres dalam kehidupannya (George, 2011).

Perempuan memiliki peningkatan resiko terhadap stroke disebabkan faktor hormonal. Berdasarkan laporan AHA dalam Heart Disease and Stroke Statistic (2012) menyatakan wanita yang mengalami menopause pada usia $<42$ tahun memiliki resiko dua kali terkena stroke dibandingkan dengan wanita yang menopause setelah uisa 42 tahun. Penggunaan obat anti depresi dapat menyebabkan obesitas, hipertensi dan perdarahan abnormal yang pada akhirnya dapat meningkatkan resiko terkena stroke (Pearson, 2011).

Responden perempuan yang memiliki skala penerimaan diri lebih rendah dibandingkan dengan laki-laki bisa disebabkan karena perempuan mengalami stres 30\% lebih tinggi dari laki-laki (Gunawati, 2006). Kondisi ini juga disebabkan karena respon fisiologis yang berbeda antara laki-laki dan perempuan. Pada saat perempuan mengalami stres, tubuh akan memberikan respon berupa perubahan aktivitas dari beberapa hormon dan neurotransmitter di otak. Perempuan memiliki prolaktin yang lebih tingi dari laki-laki sedangkan prolaktin sendiri mempunyai efek memberikan umpan balik negatif pada otak sehingga dapat meningkatkan trauma emosional dan stres fisik (Corwin, 2007).

\section{Pengaruh intervensi kognitif spiritual terhadap skala penerimaan diri pada klien stroke iskemik}

Pada tabel diatas dapat dilihat perbedaan skala penerimaan diri pada kelompok perlakuan dan kelompok pembanding pre test dan post test. Kelompok perlakuan memiliki skala penerimaan diri yang lebih tinggi daripada kelompok pembanding. Setelah lima hari dilakukan intervensi pada kelompok perlakuan, klien pada kelompok perlakuan mengalami peningkatan nilai. Peningkatan skala penerimaan diri yang paling besar dengan beda nilai 21 antara pre test dan post test terjadi pada klien perempuan usia 59 tahun dengan frekeunsi kedekatan dengan Qur'an berupa sering membaca dan paham maknanya. Pendidikan klien SMP yaitu pendidikan menengah cukup untuk klien dapat menerima rangsangan kognitif melalui auditori dan visual sehingga efek dari intervensi dapat maksimal.

Klien yang memahami bacaan Qur'an yang dibacanya dan mampu mengaplikasikan dalam kehidupan seharihari dapat membantu klien untuk beradaptasi terhadap stressor yang dimiliki. Penyakit stroke dan kelemahan yang dimiliki tidak dianggap sebagai sesuatu yang berarti sehingga klien dapat bangkit dari kesedihan aibat sTavtroke.

Hasil uji statistik mengunakan paired $t$ test mendapatkan nilai $\mathrm{p}$ sebesar 0.001 menunjukkan ada perbedaan yang signifikan antara nilai pre dan post test. 
Nilai p menunjukkan ada pengaruh intervensi kognitif spiritual pada skala penerimaan diri klien stroke. Intervensi kognitif yang merubah pikiran negatif yang fokus pada kelemahan diri dirubah menjadi pikiran positif dengan meningkatkan rasa syukur klien terhadap semua nikmat yang sudah diberikan oleh Alloh SWT dapat meningkatkan skala penerimaan diri. Klien yang awalnya merasa bahwa kelemahan diri yang dialami ini mempengaruhi kehidupan klien, bahwa kelemahan fisik mempengaruhi mental mereka menyebabkan penerimaan diri mereka rendah pada saat pre test. Kemudian perubahan persepsi tentang kelemahan diri dapat dilihat pada nilai dari pernyataan tersebut yang awalnya disetujui oleh klien berubah menjadi tidak setuju. Klien juga mengaggap bahwa pernyataan kelemahan fisik membuat semua aspek kehidupan mereka telah tertutup tidak disetujui oleh mereka dan hal ini menunjukkan persepsi postif tentang kelemahan yang dialami.

\section{KESIMPULAN}

1) Tahap penerimaan diri pada 20 klien stroke iskemik sebagian besar berada pada tahap denial. Klien tidak percaya bahwa mereka mendapatkan serangan stroke dan menganggap bahwa mereka hanya mengalami sakit sementara dan akan segera pulih. Sebagian besar klien pada kelompok perlakuan yang berada pada tahap bargaining menyesalkan ketidakpatuhan mereka untuk kontrol dan minum obat sehingga mereka mengalami stroke. Klien yang mendapatkan serangan stroke pertama harus menyesuaikan diri dengan kelemahan yang dialami. Jika klien tidak didukung dengan kesiapan mental dan spiritual untuk mengalami kelemahan tersebut, maka klien akan berada pada tahap denial.

2) Skala penerimaan diri pada klien stroke iskemik pada penelitian ini masuk dalam kategori rendah. Klien merasa bahwa kelemahan diri yang mereka alami mempengaruhi segala aspek kehidupan mereka dan berpengaruh terhadap mental mereka.

3) Intervensi kognitif spiritual dapat meningkatkan tahap penerimaan diri klien stroke iskemik. Intervensi kognitif dapat menghentikan pikiran negatif yang dialami klien sehingga klien tidak lagi berada dalam tahap denial. Penguatan sisi spiritual klien dengan membangkitkan rasa syukur ketika meresapi QS. Ar-Rahman dapat mempercepat adaptasi klien menuju tahap adaptasi selanjutnya sehingga akan mengalami acceptance terhadap kelemahan yang dimiliki.

4) Intervensi kognitif spiritual dapat meningkatkan skala penerimaan diri klien stroke iskemik.

\section{Saran}

1) Saran bagi pendidikan keperawatan Intervensi kognitif spiritual perlu digunakan dan dikembangkan bukan hanya untuk klien stroke iskemik tetapi juga untuk klien dengan sakit kronis lainnya yang membutuhkan penguatan penerimaan diri.

2) Saran bagi praktik keperawatan

Intervensi kognitif spiritual sebagai intervensi yang dapat meningkatkan penerimaan diri klien dapat digunakan sebagai salah satu tindakan mandiri keperawatan untuk menguatkan spiritual klien yang selama ini jarang tersentuh.

3) Saran bagi subyek penelitian

Klien yang menjadi subyek penelitian ini dapat meningkatkan kemampuan mengubah pikiran negatif menjadi pikiran positif dengan membangkitkan rasa syukur agar penerimaan diri semakin meningkat dan manajemen stres berhasil dilakukan.

4) Saran bagi penelitian selanjutnya Paradigma penelitian mixed method (penelitian kuantitatif dikombinasikan dengan penelitian kualitatif) dapat 
dikembangkan untuk memperoleh hasil penelitian yang lebih akurat. Instrumen baru dapat dibuat dan distandarisasi untuk mengatasi kelemahan instrumen lama.

\section{DAFTAR PUSTAKA}

Anjaryani, W.D. (2009). Kepuasan pasien rawat inap terhadap pelayanan perawat di RSUD Tugurejo Semarang. Semarang: Tesis Universitas Diponegoro. eprints.undip.ac.id. diunduh pada tanggal 10 Agustu2 2016.

Badan Penelitian dan Pengembangan Kesehatan (2008). Laporan Nasional Riskesda 2007, Badan Penelitian dan Pengembangan Kesehatan Departemen Kesehatan, Republik Indonesia. Diakses dari http://www.litbang.depkes.go.id. Diakses pada tanggal 14 November 2015.

Black,J.M., \& Hawks,J.H., 2009. Medical Surgical Nursing Clinical Management For Positive Outcomes, 8th Ed., St Louis Missouri: Elsevier Saunders.

Guyton C.A; John E.H, 2011. Text Book of Medical Physiology.Twelfth edition. Alih Bahasa Ermita I. Ibrahim Ilyas. 2014. Buku Ajar Fisiologi Kedokteran. 11th ed. F. D. Irawati, Dian Ramadhani, Fara Indriyana, ed., Jakarta: EGC.

Hidayat.,A., 2011. Pengantar Konsep Dasar Keperawatan Edisi 2., Jakarta: Salemba Medika.

Kozier, B., Glenora, E., Audrey, B., Shirlee, J.S., 2010. Buku Ajar FundamentalKeperawatan Konsep, Proses dan Prakti. Edisi 7. Vol.1. Alih Bahasa: Pamilih Eko Karyuni. Jakarta:EGC.

Lewis., 2007. Medical Surgical Nursing : Assessment \& Management of Clinical Problem. 7th ed., St.Louis: Missouri.Mosby-Year Book, Inc.
Levine, P.G., 2009. Stronger After Stroke, Panduan Lengkap dan Efektif Terapi Pemulihan Stroke. Jakarta: EGC..

McPhee., Ganong., 2010. Patofisiologi Penyakit Pengantar Menuju Kedokteran Klinis Edisi 5. Jakarta: EGC.

Mc Ewen, M. \& Wills E. 2014. Theoretical Basis for Nursing. 4th Edition. Philadelphia: Lippincott Williams \& Wilkins

Multyasih, E \& Ahmad, A., 2008. Stroke: Petunjuk Perawatan Klien Pasca Stroke di Rumah., Jakarta: Balai Penerbit FKUI.

National Stroke Association. 2009. Stroke Fact : Recovery after strokeRecurrent stroke. http://www.stroke.org. Diakses tanggal 14 November 2015.

Nursalam, 2014. Metodologi Penelitian Ilmu Keperawatan Pendekatan Praktis 3rd ed., Jakarta: Salemba Medika.

Parker., M \& Marlaine., 2010. Nursing Theories and Nursing Practice 3rd Edition. Davis Company. Philadelphia.

Pradanasari, R., 2009. Rehabilitasi Stroke pada Pelayanan Kesehatan Primer. Maj Kedokteran Indonesia., Volum: 59, Nomor: 2. Diakses 15 November

2016.http://stroke.ahajournals.org. 14 November 2015.

Petrina, B., 2010. Motor Recovery In Stroke.

http://emedicine.medscape.com. Diakes 12 Desember 2015.

Potter, P.A, Perry, A.G., 2006. Buku Ajar Fundamental Keperawatan: Konsep, Proses, dan Praktik.Edisi 4.Volume 2. Alih Bahasa : Renata Komalasari,dkk. Jakarta:EGC.

Price, S.A., \& Wilson, L.M., 2006.Patofisiologi Konsep Klinis Proses Penyakit Edisi 6. Jakarta: EGC. 
Pdpersi. 2010. Stroke, Penyebab Utama

Kecacatan

Fisik.

http://pdpersi.co.id. Diakses tanggal 4 Desember 2015.

Smeltzer, S.C., Bare, B.G., Hinkle, J.L. \& Cheever, K.H., 2008. Brunner \& Suddarth's Textbook of MedicalSurgical Nursing. 11th Ed., Philadelphia : Lippincott William $\&$ Wilkins.

Steven C. Cramer, Randolph J. Nudo.,2010. Brain Repair After Stroke. Cambridge University Press. Diakses tanggal 4 Desember 2015. 